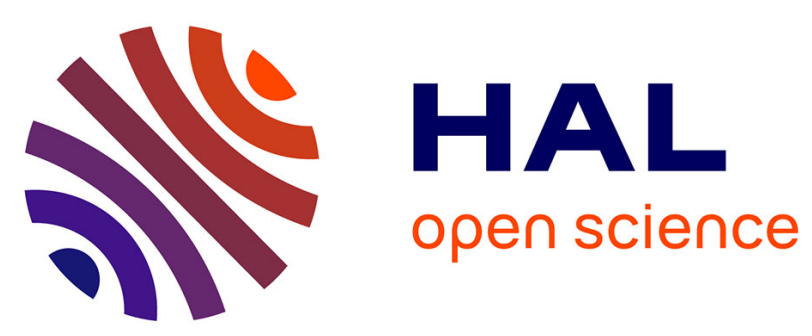

\title{
Energy and exergy optimization of food waste pretreatment and incineration
}

Yuanjun Tang, Jun Dong, Yong Chi, Zhaozhi Zhou, Mingjiang Ni

\section{To cite this version:}

Yuanjun Tang, Jun Dong, Yong Chi, Zhaozhi Zhou, Mingjiang Ni. Energy and exergy optimization of food waste pretreatment and incineration. Environmental Science and Pollution Research, 2017, 24 (22), p. 18434-18443. 10.1007/s11356-017-9396-4 . hal-01619245

\section{HAL Id: hal-01619245 \\ https://hal.science/hal-01619245}

Submitted on 8 Jan 2019

HAL is a multi-disciplinary open access archive for the deposit and dissemination of scientific research documents, whether they are published or not. The documents may come from teaching and research institutions in France or abroad, or from public or private research centers.
L'archive ouverte pluridisciplinaire HAL, est destinée au dépôt et à la diffusion de documents scientifiques de niveau recherche, publiés ou non, émanant des établissements d'enseignement et de recherche français ou étrangers, des laboratoires publics ou privés. 


\title{
Energy and exergy optimization of food waste pretreatment and incineration
}

\author{
Yuanjun Tang ${ }^{1,2} \cdot$ Jun Dong $^{1,2} \cdot$ Yong Chi $^{1} \cdot$ Zhaozhi Zhou $^{1} \cdot$ Mingjiang $\mathrm{Ni}^{1}$
}

\begin{abstract}
With the aim of upgrading current food waste (FW) management strategy, a novel FW hydrothermal pretreatment and air-drying incineration system is proposed and optimized from an energy and exergy perspective. Parameters considered include the extracted steam quality, the final moisture content of dehydrated FW, and the reactor thermal efficiency. Results show that optimal working condition can be obtained when the temperature and pressure of extracted steam are $159{ }^{\circ} \mathrm{C}$ and $0.17 \mathrm{MPa}$, the final moisture content of dehydrated FW is $10 \%$, and the reactor thermal efficiency is $90 \%$. Under such circumstance, the optimal steam energy and exergy increments reach 194.92 and $324.50 \mathrm{~kJ} / \mathrm{kg}-\mathrm{FW}$, respectively. The novel system is then applied under the local conditions of Hangzhou, China. Results show that approximately 2.7 or $11.6 \%$ (from energy or exergy analysis perspective) of electricity can be additionally generated from 1 ton of MSW if the proposed novel FW system is implemented. Besides, comparisons between energy and exergy analysis are also discussed.
\end{abstract}

Highlights $\cdot$ A novel FW hydrothermal pretreatment system is proposed. - Energy and exergy are analyzed and compared to optimize thermodynamic efficiency.

- Extracted steam quality, final moisture content, and reactor thermal efficiency are varied.

- A case study is performed with regard to local conditions of Hangzhou, China
Keywords Food waste $\cdot$ Thermal hydrolysis $\cdot$ Energy analysis $\cdot$ Exergy analyses $\cdot$ Dehydration

\section{Introduction}

Food waste (FW) occupies a relatively high mass ratio of municipal solid waste (MSW) in many countries. FW is characterized as high moisture content and low heating value, and the humid nature hence would bring adverse effects on the whole MSW management system when FW is mixed with other waste fractions. FW is easily contaminated and contains various bacteria, and thus could seriously threaten human health (Liu et al. 2016). Besides, greenhouse gases such as $\mathrm{CO}_{2}$ and $\mathrm{CH}_{4}$ produced during its biodegradation may also cause considerable environmental problems (Mahmood et al. 2016). However, apart from being a pollutant of concern, FW can also be regarded as an important bio-resource. Therefore, the proper management of FW is of great importance to minimize environmental burdens and also to achieve energy recovery.

Along with the development and popularization of waste source-separated collection, FW treatment separately from mixed MSW becomes possible. Generally, the presently available FW treatment technologies include landfill, composting, anaerobic digestion (AD), and thermal methods. Among these, landfill is the most widely used method. However, leachate and land occupation cause serious troubles (Sotiropoulos et al. 2016). Given this fact, EU has launched the Directive 2003/33/EC, regulating that waste landfill is prohibited if the total organic carbon content is higher than 5\% (Communities 2003;16). On the other hand, biological technologies, such as composting and $\mathrm{AD}$, have been recognized as effective approaches to convert FW to bio-resource (Müller 2007). Nevertheless, the applications of AD or composting in developing countries are still restricted due to 
inadequate operations, treatment capacities, long processing periods, and enrichment of heavy metals (Boldrin et al. 2010; Lundie and Peters 2005). Thermal treatments, for example incineration, can achieve both FW volume reduction and energy/heat recovery. However, incineration of FW alone seems inappropriate due to its high moisture content and low heating value. Typically, FW is usually mixed with other MSW fractions and deposited in incineration plant (Pham et al. 2015). Under such circumstance, a considerable amount of energy will be consumed for the evaporation of the moisture contained in $\mathrm{FW}$, thus leading to a significant reduction of the overall plant energy efficiency (Latif et al. 2012). Therefore, advanced processing to convert FW in an energyefficient and environmental-friendly way becomes essential.

Drying of FW before incineration is considered to be an attractive potential approach. By reducing the moisture content beforehand, mass and volume of FW could be significantly reduced, and also, its heating value can be effectively increased. The dehydrated FW can thus be regarded as a promising bioresource for subsequent use (Sotiropoulos et al. 2015). Up to date, several studies have focused on the characteristics of FW drying and/or the further processing techniques (Choi et al. 2015; Dobric 2014; Lai et al. 2009). Sotiropoulos et al. investigated the drying kinetics of $\mathrm{FW}$, indicating that $\mathrm{FW}$ drying is greatly affected by temperature and to a smaller scale by air velocity (Sotiropoulos et al. 2016). Choi et al. studied the drying characteristics of food waste mixtures by microwave/innercycle thermal-air drying method, resulting in the final moisture content of 5.8\% (Choi et al. 2015). However, pre-drying of FW is also quite energy consuming and costly, since a high amount of enthalpy is required to evaporate the moisture contained. In order to overcome such defect, thermal hydrolysis (TH) pretreatment has become a potential FW pretreatment method, which occurs prior to drying process. The concept of TH is to use water as reaction medium to break cell walls of organic matters by heat and pressure (Chen et al. 2017). Through TH pretreatment, the dewaterability of FW can be remarkably improved; meanwhile, the reaction medium (water) inside the sealed reactor is maintained in the liquid form to save the latent heat of water evaporation ( $\mathrm{Li}$ et al. 2017; Schieder et al. 2000). Realizing this advantages, John Lee introduced a series of innovations associated with the method and apparatus for the pretreatment of biodegradable organic wastes using TH pretreatment and demonstrated $\mathrm{TH}$ pretreatment followed by $\mathrm{AD}$ of the solubilized fractions, and combustion of the residues potentially provides an economically attractive and environmentally friendly disposal alternative for organic wastes (Lee Jr 2005, 2007, 2011). Yangyang Li et al. evaluated the effect of $\mathrm{TH}$ on the utilization of FW based on the principle of split phase processing, including the subsequent energy recovery from solid residues, liquid phase, and floating oil ( $\mathrm{Li}$ et al. 2016). Similar researches were also conducted by Lissens et al. (2004) and Kumar et al. (2009).
On the basis of the aforementioned knowledge, a novel FW hydrothermal pretreatment and air-drying incineration system are proposed in the present work. In the proposed system, FW is firstly hydrolyzed and dehydrated in a pretreatment system, and then, it is mixed with other MSW fractions to be treated in a incineration plant. Energy savings could be obtained from the novel FW treatment system as a result of fuel quality improvement.

However, despite of the potential benefits, the feasibility and stability of the proposed novel FW treatment system has not yet been practically examined. Therefore, a thorough thermodynamic performance evaluation of the system is essential. Energy and exergy analyses are effective thermodynamic methods for the assessment of thermal systems and are conducted in the present study (Dincer 2002; Sarker et al. 2015). Energy analysis is used to judge the system by accounting and comparing the amount of energy inputs and outputs. However, it considers only the quantity but ignores the quality of energy streams according to the conservation law, thus may unfortunately lead to misunderstandings when applied to thermal systems (Tang et al. 2016). Therefore, exergy analysis is also conducted to incorporate energy quantity and quality at the same time. Exergy is defined as the maximum potential of work obtainable from a substance or a system while it approaches to the reference environment reversibly (Yamankaradeniz 2016). By conducting exergy analysis, the thermodynamic performance of the novel FW treatment system can be identified from an energy quality perspective.

Accordingly, in the present work, the management of FW by means of hydrothermal pretreatment and air-drying incineration is proposed. Energy and exergy optimizations of the novel FW treatment system are compared to evaluate the thermodynamic performance by varying the process parameters. The effects of the extracted steam qualities, the final moisture content of the dehydrated FW, and the reactor thermal efficiency on the steam energy and exergy increments are taken into consideration. Besides, a case study under the specific condition in Hangzhou city, China, is also conducted. The obtained results could be valuable in the future to provide an energy efficient and environmental sustainable strategy for FW management.

\section{Systems and methods}

\section{Descriptions of the novel FW treatment system}

In the present study, a novel FW treatment system is proposed, as depicted in Fig. 1. Compared with conventional waste incineration (where mixed MSW is incinerated), FW is firstly pretreated in a sealed reactor by $\mathrm{TH}$ reaction at temperature of $145-170{ }^{\circ} \mathrm{C}$ for typically $10-40 \mathrm{~min}$ (Solheim and Nilsen 2014). The heating source used in this stage is from the steam 
Fig. 1 Conceptual graph of the proposed FW thermal hydrolysis pretreatment and air-drying incineration system

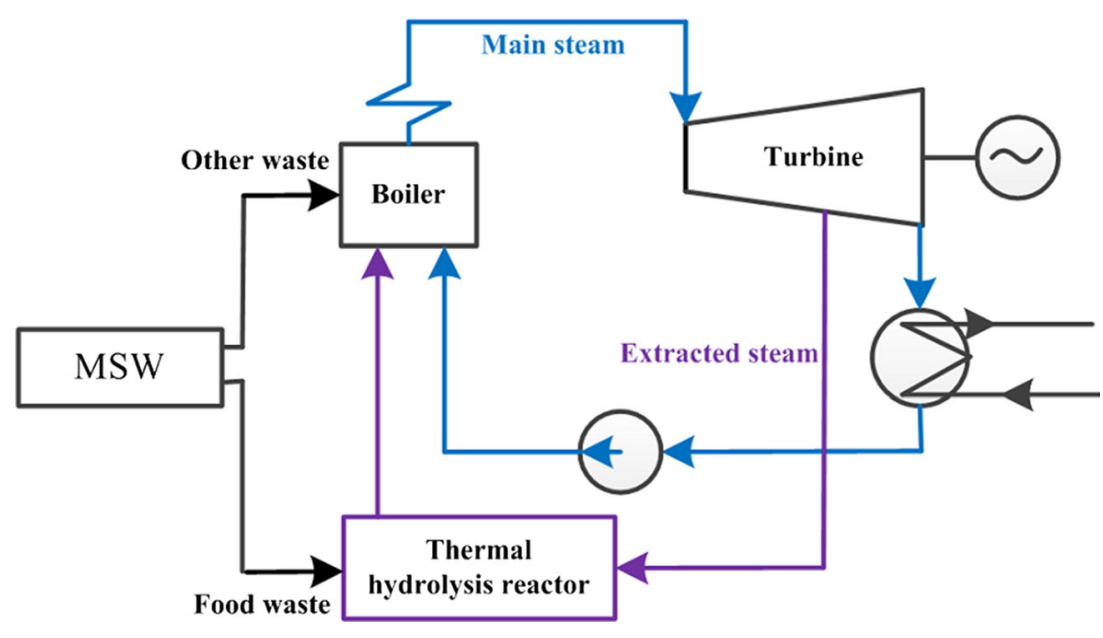

extracted at a low temperature and pressure from the turbine. When TH reaction is finished, the reactor is subjected to a quick pressure reduction, so that a fast outflow of water vapor from the reactor is achieved by flash evaporation. In this case, the waste heat from the reactor can be further recovered. By TH pretreatment, the internal structure and cell walls of FW are destroyed. And bound water inside the FW gradually converts to free water, resulting in a remarkable improvement of FW dewaterability, and the moisture contained can be easily reduced (Feng et al. 2015; Song et al. 2014).

\section{Energy analysis model development}

Based on the novel FW treatment system proposed, a thermodynamic analysis model is developed. The conventional waste incineration, which burns mixed MSW directly, is used as the comparison basis to identify the energy savings from the proposed system. In order to simplify the calculation, following assumptions are made:

(1) the temperature and pressure of high-quality main steam remain unchanged;

(2) the heat losses from the boiler are kept the same except for exhaust energy losses;

(3) the thermal efficiency of the boiler remains unchanged.

TH reaction is conducted in a batch reactor at a typical temperature of $150^{\circ} \mathrm{C}$ for $30 \mathrm{~min}$ (Liu et al. 2015; Solheim and Nilsen 2014). FW is fed into the reactor with a quantitative amount of additional water, and then is heated to the desired temperature. It is assumed that the reactor is completely filled with water and no water is evaporated inside the reactor. Heat absorbed by air in the reactor is not taken into consideration (Liu et al. 2011). Therefore, the energy absorbed by the reactor is divided into two parts, by water in the reactor and by organic matter contained in FW, which can be described as follows (Stabnikova et al. 2008):
$Q_{\text {reactor }}=\left[C_{\text {organic }} \cdot M_{\text {organic }} \cdot \Delta t+C_{\text {water }} \cdot\left(M_{\text {water }}+k\right) \cdot \Delta t\right]$

where $Q_{\text {reactor }}$ represents the energy required for reactor heating; $C_{\text {organic }}$ and $C_{\text {water }}$ are the specific heat capacity of organic matter and water with values of $0.89 \mathrm{~J} /\left(\mathrm{g}{ }^{\circ} \mathrm{C}\right)$ and $4.18 \mathrm{~J} /\left(\mathrm{g}{ }^{\circ} \mathrm{C}\right)$, respectively; $M_{\text {organic }}$ and $M_{\text {water }}$ are the mass flow rate of organic matter and moisture contained in raw $\mathrm{FW}$; $k$ is the amount of additional water; $\Delta \mathrm{t}$ is the difference between the $\mathrm{TH}$ reaction temperature $\left(150{ }^{\circ} \mathrm{C}\right)$ and the ambient temperature $\left(25^{\circ} \mathrm{C}\right)$.

As aforementioned, the $\mathrm{TH}$ process is driven by the heat energy of the steam extracted from the turbine. According to the enthalpy balance of the TH process, the extracted steam flow rate to hydrothermally pretreat $1 \mathrm{~kg}$ of $\mathrm{FW}$ can be obtained as follows:

$F_{\text {steam }}=\frac{Q_{\text {reactor }}}{\eta_{\text {reactor }} \cdot\left(h_{j}-h_{c 0}\right)}$

where $F_{\text {steam }}$ represents the extracted steam mass flow rate; $h_{j}$ and $h_{c 0}$ are the specific enthalpy of the extracted steam and condensate; $\eta_{\text {reactor }}$ stands for the thermal efficiency of reactor.

After being hydrothermally pretreated, FW is naturally dried by air for 1 day to further decrease the moisture content. And then it is mixed with other MSW fractions and fed into the incinerator. Due to the reduction of the final moisture content of the dehydrated FW, the exhaust gas heat loss from the boiler can be reduced. And the energy savings can thus be obtained from the novel FW treatment system. The energy savings of the system proposed is described as follows:

$\Delta Q_{\text {exhaust }}=F_{\text {water }} \cdot\left(h_{\text {vapor }}-h_{w 0}\right)$

where $\Delta Q_{\text {exhaust }}$ represents the energy savings due to exhaust heat energy loss reduction; $F_{\text {water }}$ is the mass of removed water from dehydrated FW; $h_{\text {vapor }}$ and $h_{w 0}$ are the specific 
enthalpies of vapor in boiler exhaust and water in dehydrated FW.

On the other hand, the energy consumption of the proposed system occurs due to steam extraction. By extracting the steam from the turbine, energy content of the steam to drive the turbine is reduced. Therefore, energy consumption can be obtained by the following:

$$
\Delta Q_{\text {steam }}=F_{\text {steam }} \cdot\left(h_{j}-h_{c 0}\right)
$$

where $\Delta Q_{\text {steam }}$ represents the energy content of extracted steam.

According to the assumptions that the temperature and pressure of the high-quality main steam remains unchanged, the overall steam energy increments of the novel FW treatment system can be obtained by comparing the difference between the energy savings and the energy consumptions as follows:

$$
\begin{aligned}
E_{\text {system }} & =\Delta Q_{\text {exhaust }}-\Delta Q_{\text {steam }} \\
& =\frac{a_{0}-a}{1-a} \times\left(h_{\text {vapor }}-h_{w 0}\right)-\frac{\left[C_{\text {organic }} \times M_{\text {organic }} \times \Delta t+C_{\text {water }} \times\left(M_{\text {water }}+k\right) \times \Delta t\right]}{\eta_{\text {reactor }}}
\end{aligned}
$$

where $E_{\text {system }}$ represents the overall steam energy increments from the novel FW treatment system; $a_{0}$ and $a$ are the moisture content of raw FW and dehydrated FW, respectively.

\section{Exergy analysis model development}

Energy analysis is based on the first law of thermodynamics, considering quantitative balance of energy flows. However, the second law of thermodynamics indicates that entropy of an irreversible process tends naturally to increase, which means the quality of energy may decrease even though its quantity remains unchanged. Especially for power generation systems, steam with the same quantity amount of energy may differ significantly in power capabilities due to the variation of temperature and pressure. Realizing this fact, an exergy analysis of the novel FW treatment system is also conducted.

To perform exergy analysis, a reference state is defined with temperature $\left(T_{0}\right)$ of $298.15 \mathrm{~K}$ and pressure $\left(P_{0}\right)$ of $101.3 \mathrm{kPa}$. Accordingly, the exergy content of a flow of substance is given as follows:

$e=e_{p h}+e_{c h}$

where $e, e_{p h}$, and $e_{c h}$ represent the exergy, physical exergy, and chemical exergy content of the flow, respectively.

The physical exergy of a fluid stream per unit mass can be obtained by the following (Mahmood et al. 2016):

$e_{p h}=\left(h-h_{0}\right)-T_{0} \cdot\left(s-s_{0}\right)+\frac{1}{2} \cdot v^{2}+g z$

where $h$ and $h_{0}$ are the specific enthalpies of the stream at a given condition and the reference state; $s$ and $s_{0}$ are the specific entropies of the stream at a given condition and the reference state; $v^{2} / 2$ and $g z$ represent the kinetic and potential exergy content of the stream. Generally, the values of kinetic exergy and potential exergy are relatively small, and thus negligible in the analysis (Zhang et al. 2012).

The chemical exergy content of a flow of substance per unit mole can be obtained by means of an exergy balance of its formation reaction as follows (Rivero and Garfias 2006):

$e_{c h}=-\sum n_{r} \cdot e_{r, m}^{0}-\Delta G\left(p_{0}, T_{0}\right)+\sum n_{p r} \cdot e_{p r, m}^{0}$

where $n_{r}$ and $n_{p r}$ represent the stoichiometric coefficients of the reactants and the products; $e_{r, m}^{0}$ and $e^{0}{ }_{p r m}$ are the exergy caused by the diffusion of reactants and the products; $\Delta G\left(p_{0}, T_{0}\right)$ is the change of Gibbs free energy caused by the formation reaction.

As discussed previously, due to the dehydrated FW moisture content reduction, the energy savings are obtained. Therefore, more energy can be available to create the high-quality main steam in the boiler. The amount of additionally generated highquality main steam can thus be estimated as follows:

$F_{\text {msteam }}=\frac{\Delta Q_{\text {exhaust }}}{\left(h_{\text {msteam }}-h_{w f}\right)}$

where Fmsteam is the mass flow rate of the additionally generated high-quality main steam; $h_{m s t e a m}$ and $h_{w f}$ are the specific enthalpies of the high-quality main steam and feed water.

Therefore, the steam exergy increments of the proposed system are determined by the exergy content of the additionally generated high-quality main steam and the exergy content of the extracted steam and can be described as follows:

$e_{\text {system }}=\frac{\Delta Q_{\text {exhaust }}}{\left(h_{\text {msteam }}-h_{w f}\right)} \cdot\left(e_{\text {msteam }}-e_{w f}\right)-F_{\text {steam }} \cdot\left(e_{j}-e_{c 0}\right)$

where $e_{\text {system }}$ represents the exergy increments of the novel FW treatment system; $e_{m s t e a m}$ and $e_{w f}$ are the specific exergy 
content of the high-quality main steam and feed water; $e_{j}$ and $e_{c o}$ are the specific exergy content of the extracted steam and condensate.

\section{System optimization}

Based on the aforementioned energy and exergy analyses model, a thermodynamic optimization of the novel FW treatment system is presented. Three varied parameters, i.e., the extracted steam quality, the final moisture content of the dehydrated FW (a), and the thermal efficiency of the reactor $\left(\eta_{\text {reactor }}\right)$, are investigated, with the purpose to evaluate the feasibility of the model as well as to obtain the optimum working condition of the system proposed. During the optimization, when comparing the effect of one parameter, the other two parameters are kept constant to reduce the interference. The original waste incineration system considered uses the Rankine cycle with steam extraction and without reheating. This system is regarded as the most typical used arrangement in a medium-scale waste incineration plant (Bianchi et al. 2014; Branchini 2015). The main operation and calculation parameters used in the calculation are presented in Table 1.

\section{Effect of the extracted steam quality}

The temperature and pressure of the extracted steam are the dominant parameters in the novel FW treatment system, since they directly determine its mass flow rate and total amount of energy consumed. Therefore, the effect of extracted steam quality is discussed. Steam extracted from different points of the turbine is selected, with the corresponding steam quality (temperature and pressure) presented in Table 2.

Table 1 Main parameters considered in the case study

\begin{tabular}{ll}
\hline Main steam mass flow rate $[\mathrm{kg} / \mathrm{s}]$ & $18.9^{\mathrm{a}}$ \\
Main steam inlet temperature $\left[{ }^{\circ} \mathrm{C}\right]$ & $430^{\mathrm{a}}$ \\
Main steam inlet pressure $[\mathrm{MPa}]$ & $3.43^{\mathrm{a}}$ \\
Condenser pressure $[\mathrm{MPa}]$ & $0.01^{\mathrm{a}}$ \\
Boiler exhaust gas temperature $\left[{ }^{\circ} \mathrm{C}\right]$ & $164^{\mathrm{a}}$ \\
Amount of additional water for thermal & 2 \\
hydrolysis reaction $[\mathrm{kg} / \mathrm{kg}]$ & $70 \%{ }^{\mathrm{b}}$ \\
Moisture content of the raw FW $\left[\mathrm{a}_{0}\right]$ & $58.15 \%{ }^{\mathrm{b}}$ \\
Typical FW mass fraction in raw $\mathrm{MSW}$ & 25 \\
Ambient temperature $\left[{ }^{\circ} \mathrm{C}\right]$ & $150^{\mathrm{c}}$ \\
Thermal hydrolysis temperature $\left[{ }^{\circ} \mathrm{C}\right]$ & $30^{\mathrm{c}}$ \\
\hline Thermal hydrolysis time $[\mathrm{min}]$ & \\
\hline
\end{tabular}

${ }^{\text {a }}$ From reference (Branchini 2015)

${ }^{\mathrm{b}}$ From reference (Dong et al. 2013)

${ }^{\mathrm{c}}$ From reference (Solheim and Nilsen 2014)
The steam energy and exergy increments of the novel FW treatment system as a function of the extracted steam are depicted in Fig. 2. Results reveal that positive steam energy and exergy increments can be obtained at these calculation conditions. From the perspective of energy analysis, the steam energy increment remains constant as $194.92 \mathrm{~kJ} / \mathrm{kg}-\mathrm{FW}$ when changing the extracted steam temperature and pressure. This means that approximately $194.92 \mathrm{~kJ}$ of additional steam energy can be acquired by hydrothermally pretreating $1 \mathrm{~kg}$ of FW in the novel FW treatment system when it is compared with the conventional mixed MSW incineration system. And the decrease of the extracted steam quality does not affect the total energy increments. It could be explained by the fact that the energy is quantitative conservation; the total amount of the energy contained in the extracted steam directly depends on the energy consumed in HT process and is kept constant under the tested conditions. Changing the temperature and pressure of the extracted steam will only lead to the variation of its mass flow rates.

However, the results are quite different from the exergy analysis perspective. The steam exergy increment is remarkably increased from 211.91 to $324.50 \mathrm{~kJ} / \mathrm{kg}-\mathrm{FW}$ with the decrease of the extracted steam quality. Among the calculation conditions, the steam extracted from the 5 th extraction point leads to the maximum exergy increment, while conversely, the extracted steam with the highest temperature and pressure leads to the inferior performance. This is mainly because the energy contained in the extracted steam is characterized as a low-quality energy source. Because the extracted low quality steam has already been used to drive the turbine beforehand and its exergy content is thus much lower than its energy content, in this manner, the energy consumed in TH pretreatment process to heat the reactor is from the extracted steam, and thus, it is characterized as low-quality energy with low exergy content. On the other hand, due to the energy savings from the novel FW treatment system, more high-quality main steam can be additionally created in the boiler. The additionally generated high-quality main steam has a higher temperature and pressure (as stated in Table $1,430{ }^{\circ} \mathrm{C}, 3.43 \mathrm{MPa}$ ), and thus has a higher exergy content. Therefore, the steam exergy increment is higher than the corresponding steam energy increment and the exergy increment is increased when decreasing the extracted steam quality.

\section{Effect of the final moisture content of dehydrated FW}

After being hydrothermally pretreated, FW is naturally dried by air to lower its moisture content, as previously mentioned. The final moisture content of the dehydrated FW directly determines the energy savings from the reduction of the exhaust gas heat energy loss. Therefore, the effect of the final moisture content is investigated, and the results are presented in Fig. 3. 
Table 2 Temperature and pressure of the steam at different extraction points

\begin{tabular}{lllll}
\hline $\begin{array}{l}\text { Steam extraction } \\
\text { point }\end{array}$ & Temperature $\left(\mathrm{T},{ }^{\circ} \mathrm{C}\right)$ & Pressure $(\mathrm{P}, \mathrm{MPa})$ & Enthalpy $\left(h, \mathrm{~kJ} \mathrm{~kg}^{-1}\right)$ & $\begin{array}{l}\text { Entropy } \\
\left(s, \mathrm{~kJ} \mathrm{~kg} \mathrm{k}^{-1}\right)\end{array}$ \\
\hline 1 & 290 & 0.7 & 3037.30 & 7.287 \\
2 & 260 & 0.53 & 2979.78 & 7.2885 \\
3 & 215 & 0.33 & 2894.34 & 7.3761 \\
4 & 187 & 0.24 & 2841.49 & 7.3894 \\
5 & 159 & 0.17 & 2789.02 & 7.4219 \\
\hline
\end{tabular}

Results reveal that lower final moisture content of the dehydrated FW could significantly facilitate the steam energy and exergy increments of the novel FW treatment system. In this calculation, when the final moisture content is decreased from 60 to $10 \%$, the steam energy and exergy increments increase from -929.77 and $-50.09 \mathrm{~kJ} / \mathrm{kg}-\mathrm{FW}$ to 194.92 and $324.50 \mathrm{~kJ} / \mathrm{kg}-\mathrm{FW}$, respectively. This is mainly attributed to the reduction of the moisture fed into the incinerator, which reduces the heat energy being taken away by the water vapor in flue gas. Hence, more high-quality main steam can be additionally created in the boiler. However, it is also worth mentioning that negative steam energy and exergy increments of the system proposed are obtained when the moisture content is higher than 20 and 50\% in energy and exergy analyses, respectively, indicating that the system does not mean absolutely energy efficient. It is quite reasonable, since the final moisture content of the dehydrated FW directly determines the total amount of the energy savings. Therefore, if the final moisture content is too high, less additional main steam energy is produced in the boiler compared with the extracted steam energy consumed in TH process. And adverse effects will thus occur to the thermodynamic behavior of the novel FW treatment system. Fortunately as previously discussed, literature results

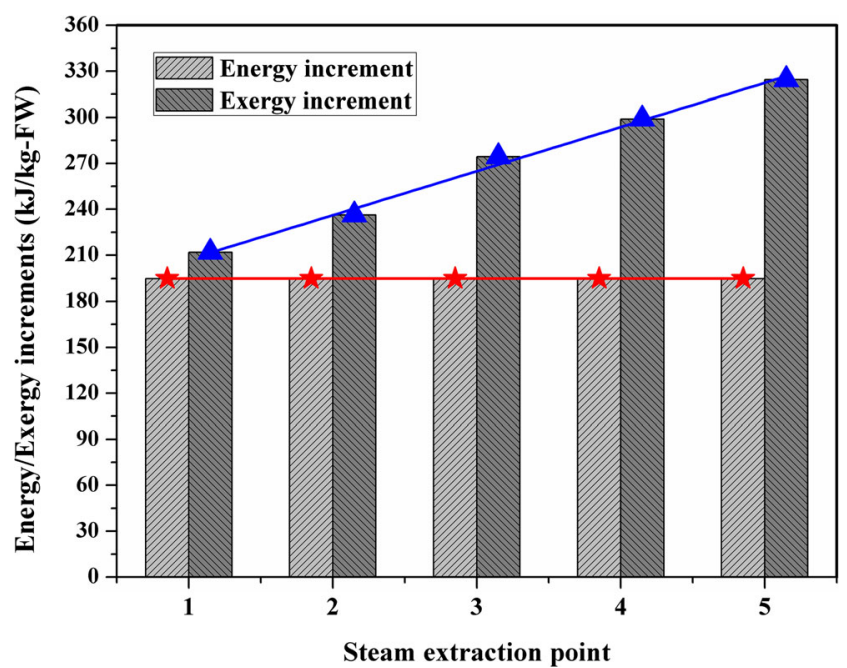

Fig. 2 Steam energy and exergy increments of the novel FW treatment system as a function of the steam extraction points (the final moisture content of the dehydrated FW is $10 \%$; the thermal efficiency of the reactor is $90 \%$ ) have demonstrated that the moisture content of the dehydrated FW can be reduced to ca. $10 \%$ after naturally air-drying due to the significant improvement of dewaterability by $\mathrm{TH}$ pretreatment (Chenglong 2013; Li et al. 2017; Sotiropoulos et al. 2016). Under such condition, the steam energy and exergy increments can reach 194.92 and $324.50 \mathrm{~kJ} / \mathrm{kg}-\mathrm{FW}$, respectively.

\section{Effect of the thermal efficiency of the TH reactor}

The influence of the $\mathrm{TH}$ reactor thermal efficiency is also evaluated, and the results of which are shown in Fig. 4. Results indicate that the steam energy and exergy increments reduce sharply from 194.92 and $324.50 \mathrm{~kJ} / \mathrm{kg}-\mathrm{FW}$ to -263.52 and $245.98 \mathrm{~kJ} / \mathrm{kg}-\mathrm{FW}$ when the reactor thermal efficiency is decreased from 90 to $70 \%$. It is notable that when the thermal efficiency is lower than $80 \%$, the negative steam energy increments are obtained, which means that more extracted steam energy is consumed compared with the additionally produced energy contained in the high-quality main steam. The reason may be attributed to the huge amount of energy losses when heating the reactor at low reactor thermal efficiencies. In this sense, positive steam energy increments can be achieved only at the conditions of thermal efficiency higher than $85 \%$. However, from the perspective of exergy analysis, positive

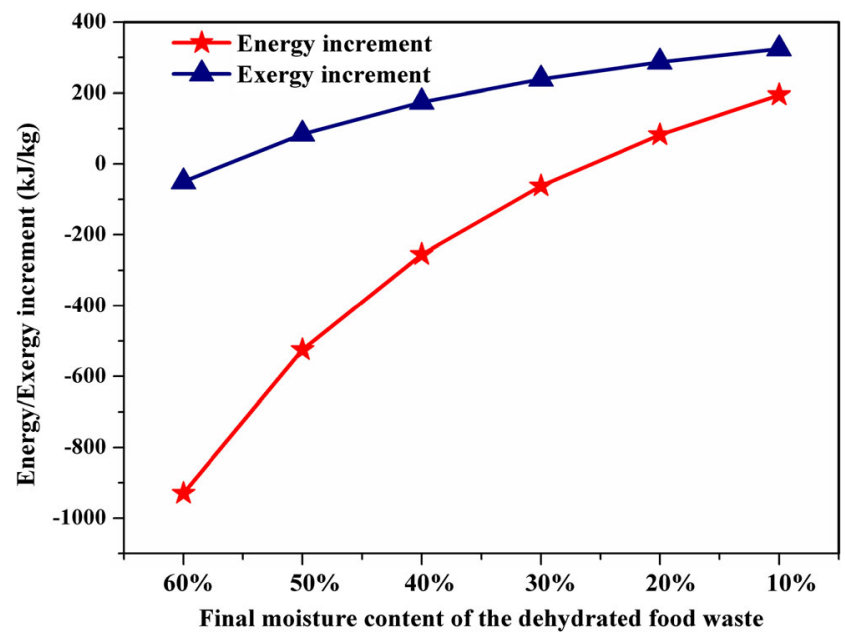

Fig. 3 Steam energy and exergy increment as a function of the moisture content of the dehydrated FW (the extracted steam is from the 5th point; the thermal efficiency of the reactor is $90 \%$ ) 


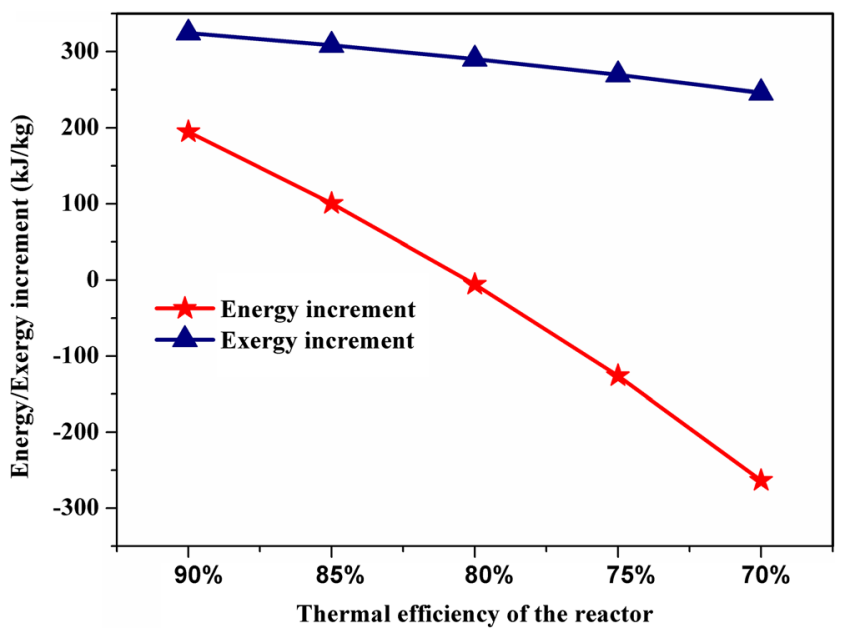

Fig. 4 Steam energy and exergy increment as a function of the reactor thermal efficiency (the extracted steam is from the 5th point; the final moisture content of the dehydrated FW is $10 \%$ )

steam exergy increments can always be obtained at the calculation conditions. This is mainly due to the exergy content difference between the low quality consumed extracted steam and the high quality additionally generated main steam. Although more steam energy is consumed under certain conditions, less extracted steam exergy content is used compared with the additional exergy generation from the high-quality main steam. Therefore, positive steam exergy increments can always be obtained under such calculation conditions.

In general, for all the calculation conditions, optimal working condition of the novel FW treatment system is obtained when the steam used for TH pretreatment is extracted from the 5th extraction point, with temperature of $159^{\circ} \mathrm{C}$ and pressure of $0.17 \mathrm{MPa}$; the final moisture content of the dehydrated FW is $10 \%$; and the thermal efficiency of the TH reactor is $90 \%$. The corresponding parameters are presented in Table 3. Under such circumstance, the novel FW treatment system steam energy and exergy increment reaches 194.92 and $324.50 \mathrm{~kJ} / \mathrm{kg}$ $\mathrm{FW}$, respectively.

Table 3 Optimal working condition of the novel FW treatment system

\begin{tabular}{lc}
\hline Parameters & Value \\
\hline Extracted steam temperature $\left[{ }^{\circ} \mathrm{C}\right]$ & $159^{\mathrm{a}}$ \\
Extracted steam pressure $[\mathrm{MPa}]$ & $0.17^{\mathrm{a}}$ \\
Moisture content of the dehydrated FW $[\%]$ & 10 \\
Reactor thermal efficiency $[\%]$ & 90 \\
Optimal energy increment $[\mathrm{kJ} / \mathrm{kg}-\mathrm{FW}]$ & 194.92 \\
Optimal exergy increment $[\mathrm{kJ} / \mathrm{kg}-\mathrm{FW}]$ & 324.50 \\
\hline
\end{tabular}

${ }^{\text {a }}$ Parameters of the steam extracted from the 5 th extraction point

\section{Case study}

After the optimization, a case study with special regard to practical condition is also conducted to estimate the overall additional amount of electricity generation from the novel FW treatment system. Hangzhou city, the capital city of Zhejiang Province in south China, is selected as the case study city. The MSW composition and ultimate analysis of food waste are presented in Table 4 (Chi et al. 2015; Dong et al. 2014). Since 2010, MSW source-separated collection project was launched in Hangzhou city. In this project, MSW was classified and collected by four categories: FW, recyclables, hazardous waste, and other residual waste, followed by different treatment methods for these waste streams (Center 2010). According to the municipal report, approximately 363.8 thousand tons of FW is separately collected and transported in Hangzhou in 2013 (Dong et al. 2013). However, this waste stream is disposed directly by landfilling instead of being efficiently recycled in the waste management system, leading to serious environmental burdens and resource depletion. Realizing this fact, the proposed FW pretreatment and incineration system are quite practicable to deal with this waste stream. Therefore, a case study is carried out to identify the achievement by implementing the novel FW treatment system under the local conditions of Hangzhou city.

The optimal working condition of the system proposed stated above is adopted for the estimation and the corresponding parameters used are listed in Table 5. The optimal steam energy and exergy increments are 194.92 and $324.50 \mathrm{~kJ} / \mathrm{kg}$ FW, respectively. As for the electricity generated from the subsequent turbine-generator system, the average steam energy and exergy to electricity efficiencies are 31.6 and $81.01 \%$, respectively (Baran et al. 2016).

Under such circumstance, the additionally generated electricity by $\mathrm{TH}$ pretreatment of $1 \mathrm{~kg}$ of the source-separated collected FW from the proposed system can be estimated as $0.0171 \mathrm{kWh} / \mathrm{kg}-\mathrm{FW}$ from energy analysis and $0.0730 \mathrm{kWh} /$ $\mathrm{kg}-\mathrm{FW}$ from exergy analysis. The total amount of the additional electricity generation can be obtained by the following:

$U_{e n}=0.0171 \mathrm{kWh} / \mathrm{kg}-\mathrm{FW} \times M_{F W}$

$U_{e x}=0.0730 \mathrm{kWh} / \mathrm{kg}-\mathrm{FW} \times M_{F W}$

where $U_{e n}$ and $U_{e x}$ are the additionally generated electricity from the novel FW treatment system from energy and exergy perspective, respectively; $M_{F W}$ is the total amount of the separated collected FW treated in the proposed system.

To better reflect the effect of the proposed system, a parallel comparison between conventional mixed MSW incineration system and the proposed novel FW hydrothermal pretreatment and air-drying incineration system are discussed. For conventional mixed MSW incineration system, a 
Table 4 MSW composition and ultimate analysis of food waste in Hangzhou

\begin{tabular}{lllllllll}
\hline \multicolumn{7}{l}{ MSW composition, content (wt.\%) } \\
Food waste & Paper & Plastics & Textiles & Glass & Metals & Wood & Slag & LHV (MJ/kg) \\
58.15 & 13.27 & 18.81 & 1.47 & 2.73 & 0.96 & 2.61 & 2 & 4.31 \\
\multicolumn{2}{l}{ Ultimate analysis and moisture content of food waste (wt.\% dry basis) } \\
$\mathrm{C}$ & $\mathrm{H}$ & $\mathrm{O}$ & $\mathrm{N}$ & & $\mathrm{S}$ & & Moisture (wt.\%) \\
48 & 6.4 & 37.6 & & 2.6 & & 0.4 & & 70 \\
\hline
\end{tabular}

commercial incinerator located in Hangzhou city is selected with a treatment capacity of 1200 ton/day. The electricity generation efficiency is estimated to be approximately $20 \%$ based on the lower heating value of mixed MSW (Dong et al. 2014). Therefore, the electricity generation amount of 1 ton mixed MSW is calculated as $367.4 \mathrm{kWh}$.

When the proposed system is implemented, the hydrothermally pre-treated food waste is mixed with the separately collected other waste according to the initial mass ratio and fed into the incinerator in order to make sure the consistence of the total amount of combustible substances. Under such circumstance, the total electricity generation amount of $581.5 \mathrm{~kg}$ food waste and $418.5 \mathrm{~kg}$ other waste (equal to 1 ton of mixed collected MSW) is 377.4 or $409.9 \mathrm{kWh}$ from energy or exergy analysis perspective. In this sense, approximately 2.7 or $11.6 \%$ (from energy or exergy analysis perspective) of electricity can be additionally generated for 1 ton of MSW if the proposed novel FW system is implemented.

\section{Comparisons and recommendations}

Based on the obtained results, a comparison between energy analysis and exergy analysis is discussed. In this study, both the two analysis methods are used to evaluate and optimize the thermodynamic behavior of the proposed novel FW treatment system. Results reveal the fact that under all the calculation conditions, the steam exergy increment of the steam is always higher than the corresponding steam energy increments. Even conflicting conclusions would be obtained from several circumstances. In order to better understand the differences

Table 5 Parameters used to estimate the overall additional electricity generation from the novel FW treatment system

\begin{tabular}{llll}
\hline Parameter & $\begin{array}{l}\text { Annual amount of } \\
\text { source separate collected } \\
\text { FW [thousand ton] }\end{array}$ & $\begin{array}{l}\text { Steam energy to } \\
\text { electricity } \\
\text { efficiency [\%] }\end{array}$ & $\begin{array}{l}\text { Steam exergy to } \\
\text { electricity } \\
\text { efficiency [\%] }\end{array}$ \\
\hline Value & $363.80^{\mathrm{a}}$ & $31.60 \%^{\mathrm{b}}$ & $81.01 \%^{\mathrm{c}}$ \\
\hline
\end{tabular}

${ }^{\text {a }}$ From reference (Dong et al. 2013)

${ }^{\mathrm{b}}$ From reference (Baran et al. 2016)

${ }^{\mathrm{c}}$ Estimated according to steam energy to electricity efficiency between energy and exergy analysis, a detailed calculation case is presented and discussed as following.

Figure 5 represents the calculation details of a specific working condition, in which the steam is extracted from the 5 th extraction point, the final moisture content of the dehydrated $\mathrm{FW}$ is $10 \%$, and the reactor thermal efficiency is $75 \%$. In this condition, when energy analysis is applied, the energy content of the extracted steam $(1925.5 \mathrm{~kJ})$ is higher than the energy content of the additionally generated highquality main steam $(1799.5 \mathrm{~kJ})$, resulting in a negative steam energy increment of $-125.99 \mathrm{~kJ} / \mathrm{kg}-\mathrm{FW}$. Therefore, the conclusion can be drawn that the implementation of the novel FW treatment system is not energy efficient under such condition. However, from the perspective of exergy analysis, a positive steam exergy increment of $269.53 \mathrm{~kJ} / \mathrm{kg}-\mathrm{FW}$ is obtained, since the exergy content of the extracted steam is lower than that of the additionally generated high-quality steam. Therefore, more electricity can be generated from the system since the steam exergy content (i.e., the energy potential to do work) is increased. Obviously, conflicting conclusions are obtained. This phenomenon can be explained by the difference of energy quality of steam. In energy analysis, the extracted steam is considered identical with the high-quality main steam when they contain the same amount of energy; however, this kind of calculation ignores their difference in the energy quality, i.e., the extracted steam exhibits a lower quality than the main steam since its temperature and pressure is lower. Nevertheless, this problem can be overcome from an exergy analysis perspective by taking into account the energy quality. Therefore, energy analysis alone may lead to misunderstandings, and exergy analysis is essential for the evaluation of thermal systems.

Overall, the different analysis results from the two methods could eventually attribute to the fact that energy analysis focuses on the quantitative balance of the input and output energy streams of a system with ignoring the energy quality, while exergy analysis incorporates both the quantity and quality of different energy forms. Therefore, exergy analysis can be regarded as a good supplement to energy analysis. However, compared to energy analysis, exergy analysis has not received enough attention and is not always conducted when evaluating thermal systems. Therefore, it is strongly recommended that exergy analysis, besides the most commonly used energy analysis, is also essential to be conducted 
Fig. 5 Calculation details of the novel FW treatment system at conditions of the steam extracted from the 5 th point, the final moisture content of $10 \%$, and the reactor thermal efficiency of $75 \%$

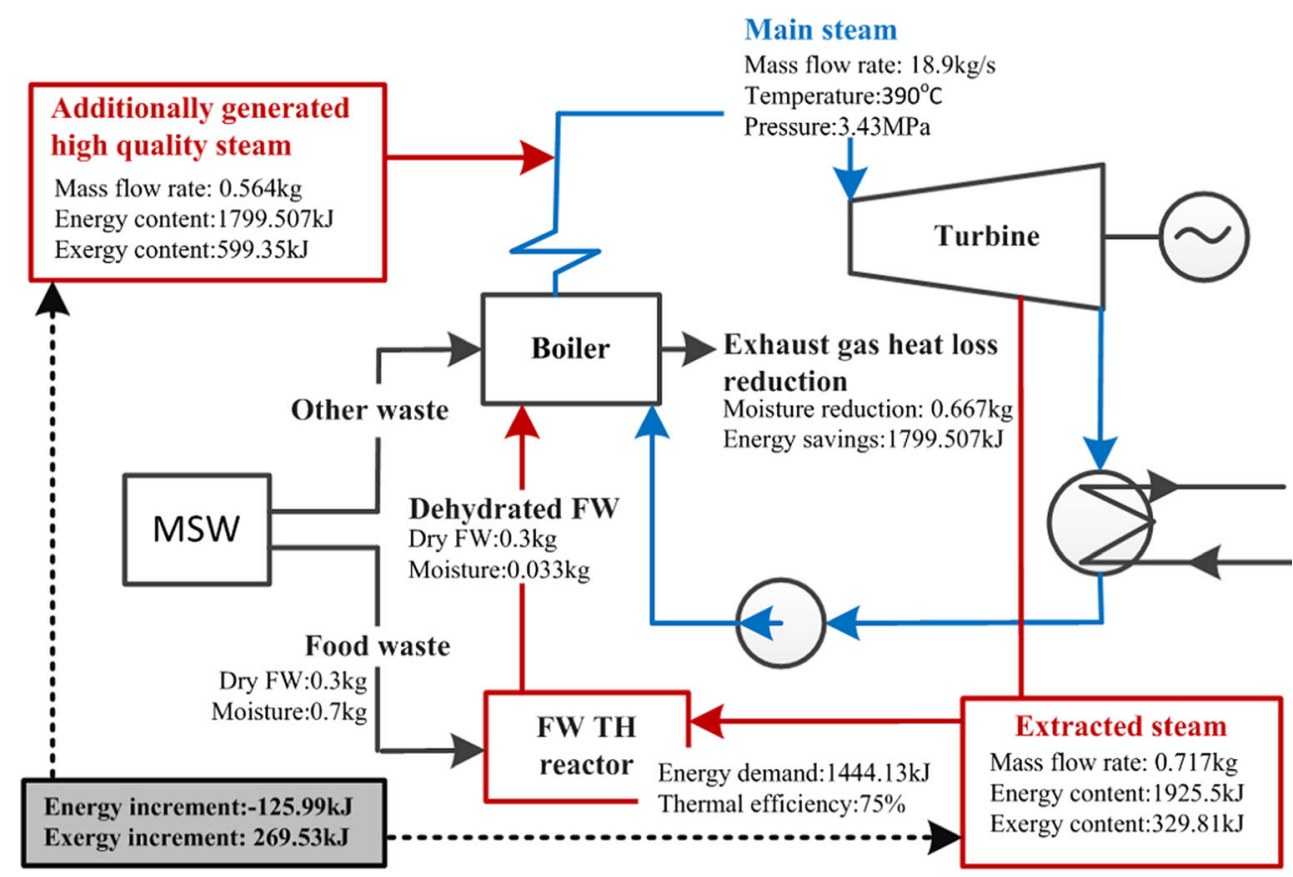

to better understand the thermodynamic behavior of a target energy system.

\section{Conclusions}

The novel FW treatment system based on TH pretreatment and air-drying incineration is proposed and optimized. Results reveal that under the calculation conditions, the optimal performance is achieved when the temperature and pressure of the extracted steam are $159{ }^{\circ} \mathrm{C}$ and 0.17 , the final moisture content of the dehydrated $\mathrm{FW}$ is $10 \%$, and the reactor thermal efficiency is $90 \%$. The optimal steam energy and exergy increments reach 194.92 and $324.50 \mathrm{~kJ} / \mathrm{kg}-\mathrm{FW}$. The case study indicates that approximately 2.7 or $11.6 \%$ (from energy or exergy analysis perspective) of electricity can be additionally generated for 1 ton of MSW if the sourceseparated collected FW is firstly pre-treated in the novel FW treatment system and then managed with other waste in incineration plant.

Acknowledgements This project is supported by the National Natural Science Foundation of China (No. 51676170) and the Program of Introducing Talents of Discipline to University (B08026).

\section{References}

Baran B, Mamis MS, Alagoz BB (2016) Utilization of energy from waste potential in Turkey as distributed secondary renewable energy source. Renew Energy 90:493-500
Bianchi M, Branchini L, De Pascale A (2014) Combining waste-toenergy steam cycle with gas turbine units. Appl Energy 130:764773

Boldrin A, Hartling KR, Laugen M, Christensen TH (2010) Environmental inventory modelling of the use of compost and peat in growth media preparation. Resour Conserv Recycl 54:1250-1260

Branchini L (2015) Waste-to-energy: advanced cycles and new design concepts for efficient power plants. Springer

Center HMSWDaS (2010) Hangzhou municipal solid waste physical property analysis and disposal method. Hangzhou

Chen B-Y, Zhao B-C, Li M-F, Liu Q-Y, Sun R-C (2017) Fractionation of rapeseed straw by hydrothermal/dilute acid pretreatment combined with alkali post-treatment for improving its enzymatic hydrolysis. Bioresour Technol 225:127-133

Chenglong F (2013) Experimental study on the thermal hydrolysis pretreatment of mechanical dewatering sewage sludge. Zhejiang University, Hangzhou

Chi Y, Dong J, Tang Y, Huang Q, Ni M (2015) Life cycle assessment of municipal solid waste source-separated collection and integrated waste management systems in Hangzhou, China. J Mater Cycles Waste Manage 17:695-706

Choi Y-i, Jung B-g, Sung N-c, Han Y-r (2015) A study on the drying characteristics from mixture of food waste and sawdust by using microwave/inner-cycle thermal-air drying process. J Mater Cycles Waste Manage 17:359-368

Council EU (2003) Council Decision 2003/33/EC of 19 December 2002 establishing criteria and procedures for the acceptance of waste at landfills persuant to Article 16 of and Annex II to Directive 1999/31/ EC[J]. OJEC 16(2003): L11

Dincer I (2002) The role of exergy in energy policy making. Energy Policy 30:137-149

Dobric S (2014) Utilizing waste heat from metal industry for drying of organic waste

Dong J, Ni M, Chi Y, Zou D, Fu C (2013) Life cycle and economic assessment of source-separated MSW collection with regard to greenhouse gas emissions: a case study in China. Environ Sci Pollut Res 20:5512-5524 
Dong J, Chi Y, Zou D, Fu C, Huang Q, Ni M (2014) Comparison of municipal solid waste treatment technologies from a life cycle perspective in China. Waste Manag Res 32:13-23

Feng G, Guo Y, Tan W (2015) Effects of thermal hydrolysis temperature on physical characteristics of municipal sludge. Water Sci Technol 72:2018-2026

Kumar P, Barrett DM, Delwiche MJ, Stroeve P (2009) Methods for pretreatment of lignocellulosic biomass for efficient hydrolysis and biofuel production. Ind Eng Chem Res 48:3713-3729

Lai C-M, Ke G-R, Chung M-Y (2009) Potentials of food wastes for power generation and energy conservation in Taiwan. Renew Energy 34:1913-1915

Latif M, Ahmad A, Ghufran R, Wahid Z (2012) Effect of temperature and organic loading rate on upflow anaerobic sludge blanket reactor and $\mathrm{CH} 4$ production by treating liquidized food waste. Environ Prog Sustain Energy 31:114-121

Lee Jr JW (2005) Method and apparatus for the treatment of particulate biodegradable organic waste. US Patents

Lee Jr JW (2007) Apparatus for the treatment of particulate biodegradable organic waste. US Patents

Lee Jr JW (2011) Treatment of particulate biodegradable organic waste by thermal hydrolysis using condensate recycle. US Patents

Li W, Guo J, Cheng H, Wang W, Dong R (2017) Two-phase anaerobic digestion of municipal solid wastes enhanced by hydrothermal pretreatment: viability, performance and microbial community evaluation. Appl Energy 189:613-622

Li Y, Jin Y, Li J (2016) Enhanced split-phase resource utilization of kitchen waste by thermal pre-treatment. Energy 98:155-167

Lissens G, Thomsen AB, De Baere L, Verstraete W, Ahring BK (2004) Thermal wet oxidation improves anaerobic biodegradability of raw and digested Biowaste. Environ Sci Technol 38:3418-3424

Liu H, Ma X, Xie C (2016) Influence of microwave drying on the combustion characteristics of food waste. Dry Technol

Liu M, Yan J, Bai B, Chong D, Guo X, Xiao F (2011) Theoretical study and case analysis for a predried lignite-fired power system. Dry Technol 29:1219-1229

Liu Y, Li X, Kang X (2015) Effect of volume ratio on anaerobic codigestion of thermal hydrolysis of food waste with activated sludge. Int Biodeterior Biodegrad 102:154-158

Lundie S, Peters GM (2005) Life cycle assessment of food waste management options. J Clean Prod 13:275-286
Müller C (2007) Anaerobic digestion of biodegradable solid waste in low-and middle-income countries. Sandec Report

Mahmood R, Parshetti GK, Balasubramanian R (2016) Energy, exergy and techno-economic analyses of hydrothermal oxidation of food waste to produce hydro-char and bio-oil. Energy 102:187-198

Pham TPT, Kaushik R, Parshetti GK, Mahmood R, Balasubramanian R (2015) Food waste-to-energy conversion technologies: current status and future directions. Waste Manag 38:399-408

Rivero R, Garfias M (2006) Standard chemical exergy of elements updated. Energy 31:3310-3326

Sarker MSH, Ibrahim MN, Aziz NA, Punan MS (2015) Energy and exergy analysis of industrial fluidized bed drying of paddy. Energy 84:131-138

Schieder D, Schneider R, Bischof F (2000) Thermal hydrolysis (TDH) as a pretreatment method for the digestion of organic waste. Water Sci Technol 41:181-187

Solheim OE, Nilsen PJ (2014) Method and device for thermal biological breakdown and dewatering of biomass. Google Patents

Song HW, Park KJ, Han SK, Jung HS (2014) Thermal conductivity characteristics of dewatered sewage sludge by thermal hydrolysis reaction. J Air Waste Manage Assoc 64:1384-1389

Sotiropoulos A, Malamis D, Loizidou M (2015) Dehydration of domestic food waste at source as an alternative approach for food waste management. Waste Biomass Valoriz 6:167-176

Sotiropoulos A, Malamis D, Michailidis P, Krokida M, Loizidou M (2016) Research on the drying kinetics of household food waste for the development and optimization of domestic waste drying technique. Environ Technol 37:929-939

Stabnikova O, Liu X, Wang J (2008) Digestion of frozen/thawed food waste in the hybrid anaerobic solid-liquid system. Waste Manag 28: 1654-1659

Tang Y, Dong J, Chi Y, Zhou Z, Ni M (2016) Energy and exergy analyses of fluidized-bed municipal solid waste air gasification. Energy Fuel 30:7629-7637

Yamankaradeniz N (2016) Thermodynamic performance assessments of a district heating system with geothermal by using advanced exergy analysis. Renew Energy 85:965-972

Zhang Y, Li B, Li H, Zhang B (2012) Exergy analysis of biomass utilization via steam gasification and partial oxidation. Thermochim Acta 538:21-28 